Pacific Journal of Mathematics

SHEAVES AND FUNCTIONAL CALCULUS

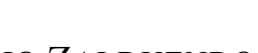




\section{SHEAVES AND FUNCTIONAL CALCULUS}

\section{G. Deferrari, A. LARotonda AND I. Zalduendo}

Let $A$ be a commutative Banach algebra with identity over the complex field, $\mathbb{C}$. Let $a_{1}, \ldots, a_{n}$ be elements of $A$, and $\operatorname{sp}(a)$ their joint spectrum. In this paper we seek to characterize the functional calculus

$$
T_{a}: \mathscr{O}(\operatorname{sp}(a), A) \rightarrow A
$$

as part of a cohomology sequence of certain sheaves, and the algebra $A$ as the algebra of sections

$$
H^{0}(\operatorname{sp}(a), \mathscr{A})=A
$$

of a sheaf $\mathscr{A}$, which is related to the Putinar structural sheaf. This is obtained under certain conditions on $a_{1}, \ldots, a_{n}$. The problem is related also to the unique extension property and to the local analytic spectrum $\sigma(a, x)$ of $x$ with respect to $a$.

Section 2 is devoted to attacking this problem. In $\S 1$, some preliminary results are obtained. We also prove that if $\sigma(a, x)$ is empty, then $x$ is nilpotent.

1. Let us start by briefly recalling (some details may be found in [2], [5]) the construction of a holomorphic functional calculus morphism

$$
T_{a}: \mathscr{O}(\operatorname{sp}(a), A) \rightarrow A .
$$

Let $U$ be an open neighborhood of $\operatorname{sp}(a)$, and $u_{1}, \ldots, u_{n}, \psi$ infinitely differentiable $A$-valued functions defined on $U$ and verifying:

(i) $\sum_{i=1}^{n} u_{i}(z)\left(z_{i}-a_{i}\right)+\psi(z)=1$, for all $z$ in $U$.

(ii) $\psi$ has compact support contained in $U$.

(iii) $\psi=1$ in some neighborhood of $\operatorname{sp}(a)$.

Then

$$
T_{a}^{U}(f)=f(a)=n !(2 \pi i)^{-n} \int_{U} f d u_{1} d z_{1} \cdots d u_{n} d z_{n}
$$

defines a continuous $A$-linear morphism from $\mathscr{O}(U, A)$ to $A$. The compatibility of these morphisms as $U$ varies over open neighborhoods of $\operatorname{sp}(a)$ produces $T_{a}$. We have the following theorem, where $U$ denotes a neighborhood of $\operatorname{sp}(a)$. 
THEOREM 1.1. Let $f \in \mathscr{O}(U, A)$, and suppose there are $g_{1}, \ldots, g_{n}$ in $C^{\infty}(U, A)$ such that

$$
f(z)=\sum_{i=1}^{n} g_{i}(z)\left(z_{i}-a_{i}\right) \text { for all } z \text { in } U .
$$

Then there exists an A-valued differential $2 n$-form $\alpha$ over $U$, verifying:

(i) $\left(z_{i}-a_{i}\right) \alpha=0$ for $i=1, \ldots, n$; and $f \alpha=0$.

(ii) For every $h$ in $\mathscr{O}(U, A)$.

$$
n !(2 \pi i)^{-n} \int_{U} h \alpha=f(a)^{n} h(a)
$$

Proof. Let $u_{1}, \ldots, u_{n}, \psi$ be as above, and let $f_{k}=u_{k} f, q_{k}=g_{k} \psi$, and $r_{j k}=g_{k} u_{j}-u_{k} g_{j}$. Then

$$
\begin{aligned}
g_{k}-f_{k} & =g_{k}\left(\sum_{j=1}^{n} u_{j}\left(z_{j}-a_{j}\right)+\psi\right)-u_{k} \sum_{j=1}^{n} g_{j}\left(z_{j}-a_{j}\right) \\
& =\sum_{j=1}^{n} r_{j k}\left(z_{j}-a_{j}\right)+q_{k} .
\end{aligned}
$$

Also

$$
\sum_{j=1}^{n} f_{j}\left(z_{j}-a_{j}\right)=(1-\psi) f=f-\psi f
$$

and therefore, differentiating and multiplying by $d z_{1} \cdots d z_{n}$,

$$
\sum_{j=1}^{n}\left(z_{j}-a_{j}\right) d f_{j} d z_{1} \cdots d z_{n}=-d(\psi f) d z_{1} \cdots d z_{n} .
$$

Since $\operatorname{supp}(\psi f)$ and $\operatorname{supp}\left(q_{k}\right)$ are compact sets contained in $U$, we may proceed as in [5] (III, 4.9), and obtain an $n-1$ differential form $\tau$ with $\operatorname{supp}(\tau)$ contained in $U$ and such that

(1) $d \tau d z_{1} \cdots d z_{n}=d g_{1} d z_{1} \cdots d g_{n} d z_{n}-d f_{1} d z_{1} \cdots d f_{n} d z_{n}$

$$
=d g_{1} d z_{1} \cdots d g_{n} d z_{n}-f^{n} d u_{1} d z_{1} \cdots d u_{n} d z_{n}
$$

Now set

$$
\begin{aligned}
\alpha & =d g_{1} d z_{1} \cdots d g_{n} d z_{n} \quad \text { and } \\
\omega & =d u_{1} d z_{1} \cdots d u_{n} d z_{n} .
\end{aligned}
$$


Differentiating $f$ we obtain

$$
d f=\sum_{j=1}^{n} g_{j} d z_{j}+\sum_{j=1}^{n}\left(z_{j}-a_{j}\right) d g_{j}
$$

and multiplying by $d g_{1} d z_{1} \cdots \widehat{d g_{k}} d z_{k} \cdots d g_{n} d z_{n}$,

$$
0=\left(z_{k}-a_{k}\right) \alpha .
$$

Multiplying by $g_{k}$ and adding gives $f \alpha=0$ and so, (i) is proved.

Now let $h$ be an element of $\mathscr{O}(U, A)$. By (1), (2), and (3) we have

$$
h \alpha-h f^{n} \omega=h d \tau d z_{1} \cdots d z_{n}=d(h \tau) d z_{1} \cdots d z_{n} .
$$

Hence, by construction of the functional calculus,

$$
n !(2 \pi i)^{-n} \int_{U} h-h(a) f(a)^{n}=n !(2 \pi i)^{-n} \int_{U} d(h \tau) d z_{1} \cdots d z_{n}
$$

but this is zero by Stokes' theorem, for $\operatorname{supp}(h \tau)$ is contained in $U$.

COROLlARY 1.2. Under the hypothesis of the theorem, $f(a)^{n+1}=0$.

Proof. Simply put $h=f$.

Corollary 1.3. Let $U$ be an open neighborhood of $\operatorname{sp}(a)$, and $f \in$ $\mathscr{O}(U, A)$. Suppose that for every $z^{0}$ in $U$, there are $f_{1}, \ldots, f_{n}$ infinitely differentiable functions near $z^{0}$ such that

$$
f(z)=\sum_{i=1}^{n} f_{i}(z)\left(z_{i}-a_{i}\right) \text { for } z \text { near } z^{0} .
$$

Then $f(a)^{n+1}=0$.

Proof. A partition of unity will put us in a situation where the theorem is applicable.

Now suppose $x$ is an element of $A$ and consider $\sigma(a, x)$, the local analytic spectrum of $x$ with respect to $a$ ([1], [4]). Putting $f=x$, we obtain that if $\sigma(a, x)$ is empty, then $x^{n+1}=0$. The conclusion $x=0$ is known only under additional hypotheses [4].

2. Let $\mathscr{O}^{A}$ be the sheaf of germs of holomorphic $A$-valued functions over $\mathbb{C}^{n}$. If $a=\left(a_{1}, \ldots, a_{n}\right) \in A^{n}$, the morphism $\lambda_{a}:\left(\mathscr{O}^{A}\right)^{n} \rightarrow \mathscr{O}^{A}$ defined by

$$
\lambda_{a}\left(f_{1}, \ldots, f_{n}\right)=\sum_{i=1}^{n}\left(z_{i}-a_{i}\right) f_{i}
$$


induces an exact sequence of sheaves

$$
0 \rightarrow \mathscr{N}_{a} \rightarrow\left(\mathscr{O}^{A}\right)^{n} \rightarrow \mathscr{O}^{A} \rightarrow \mathscr{A} \rightarrow 0 .
$$

Here the stalk of $\mathscr{N}_{a}$ over $z^{0}, \mathscr{N}_{a^{0}}$, consists of germs of $n$-tuples $\left(g_{1}, \ldots, g_{n}\right)$ of functions analytic near $z^{0}$ and verifying $\sum\left(z_{i}-a_{i}\right) g_{i}=$ 0 in some neighborhood of $z^{0} \cdot \mathscr{A}_{z^{0}}=\mathscr{O}_{z^{0}}^{A} / \mathscr{J}_{z^{0}}$, where $\mathscr{J} \subset \mathscr{O}^{A}$ is the sheaf of ideals generated by $\left(z_{i}-a_{i}\right)$ for $i=1, \ldots, n$. Note that if $z^{0}$ is not in $\operatorname{sp}(a), \mathscr{J}_{z^{0}}=\mathscr{O}_{z^{0}}^{A}$, and therefore $\mathscr{A}_{z^{0}}=0$.

Clearly, if $U$ is an open, holomorphically convex subset of $C^{n}$, then

$$
\begin{aligned}
H^{0}\left(U, \mathscr{N}_{a}\right) & =\mathscr{N}_{a}(U) \\
& =\left\{\left(f_{1}, \ldots, f_{n}\right) \in \mathscr{O}(U, A)^{n}: \sum_{i=1}^{n}\left(z_{i}-a_{i}\right) f_{i}=0\right\} .
\end{aligned}
$$

On the other hand, if $I(U)$ denotes the ideal generated by $\left(z_{i}-a_{i}\right)$, $i=1, \ldots, n$ in $\mathscr{O}(U, A)$, then $I(U) \subset H^{0}(U, \mathcal{J})$, but the equality does not, in general, hold.

Suppose $U$ contains the joint spectrum of $a_{1}, \ldots, a_{n}$. Since $T_{a}^{U}\left(z_{i}-a_{i}\right)=0$ for $i=1, \ldots, n$; we have the inclusion $I(U) \subset$ $\operatorname{Ker} T_{a}^{U}$. The following proposition shows that the ideals are the same.

Proposition 2.1. Let $U$ be a holomorphically convex open neighborhood of $\operatorname{sp}(a)$. Then $\operatorname{Ker} T_{a}^{U}=I(U)$.

Proof. The ideal of $\mathscr{O}(U \times U, \mathbb{C})$ generated by the functions

$$
(z, w) \mapsto z_{i}-w_{i}, \quad i=1, \ldots, n,
$$

is the ideal of functions analytic on $U \times U$ and zero on the diagonal $\Delta \subset U \times U$, for both ideals are closed, and they coincide locally.

Since $\mathscr{O}(U \times U, A)=\mathscr{O}(U \times U, \mathbb{C}) \otimes_{\varepsilon} A$, it follows from [3] that all $g: U \times U \rightarrow A$ null over $\Delta$ belong to the ideal generated by $\left(z_{i}-w_{i}\right)$, for $i=1, \ldots, n$.

Therefore, it $f \in \mathscr{O}(U, A)$, there are analytic $g_{k}: U \times U \rightarrow A$, such that

$$
f(z)-f(w)=\sum_{k=1}^{n} g_{k}(z, w)\left(z_{k}-w_{k}\right) .
$$

Applying the functional calculus morphism in the $w$-variable,

$$
f(z)-f(a)=\sum_{k=1}^{n} g_{k}(z, a)\left(z_{k}-a_{k}\right) \text {. }
$$

Hence, if $f(a)=0, f \in I(U)$. 
Now we can relate this fact with the homological approach of Putinar ([7]; see also [6]); to do this we consider the presheaf $\mathscr{P}$ over $\mathbb{C}^{n}$ defined by

$$
\mathscr{P}(U)=\mathscr{O}(U) \hat{\otimes}_{\mathscr{O}\left(\mathbb{C}^{n}\right)} A \quad\left(U \text { open, } U \in \mathbb{C}^{n}\right),
$$

and let $\mathscr{F}$ be the sheaf defined by $\mathscr{P}$. The standard definitions ([6]) give the identification

$$
\mathscr{P}(U)=\mathscr{O}^{A}(U) / I(U) .
$$

Hence looking at the germs we have

LEMMA 2.2. The sheaf $\mathscr{A}$ is the sheaf $\mathscr{F}$ defined by the presheaf $\mathscr{P}=\mathscr{O} \hat{\otimes}_{\mathscr{O}\left(C^{n}\right)} A$.

We also have the following fact:

Proposition 2.3. Let $U$ be a holomorphically convex open neighborhood of $\operatorname{sp}(a)$. Then

(i) The functional calculus induces a topological isomorphism

$$
\mathscr{P}(U) \approx A
$$

(ii) The kernel of the canonical map

$$
\mathscr{P}(U) \rightarrow \mathscr{A}(U)
$$

consists of nilpotent elements.

Proof. The first assertion follows easily from Proposition 2.1 and $(*)$ above, since $I(U)$ is closed in $\mathscr{O}(U, A)$. For the second, let $f \in \mathscr{O}^{A}(U)$ and assume that the image of $f$ is zero in $\mathscr{A}(U)$; this means that the class of the germ of $f$ in $\mathscr{A}_{z}$ is zero for every $z \in U$.

Then for every $z^{0} \in U$ we have an $n$-tuple $\left(g_{g_{1}}^{z^{0}}, \ldots, g_{n}^{z^{0}}\right)$ of functions analytic near $z^{0}$ such that $f=\sum\left(z_{i}-a_{i}\right) g_{i}^{z^{0}}$ in some neighborhood of $z^{0}$.

Using a partition of unity we are in the situation of Corollary 1.3; hence $f(a)^{n+1}=0$. But this implies $f^{n+1} \in I(U)$ and this means that $f^{n+1}=0$ in $\mathscr{P}(U)$.

We shall now study, for a neighborhood $U$ of $\operatorname{sp}(a)$, the cohomology sequence resulting from the exact sequence of sheaves

$$
0 \rightarrow \mathscr{J} \rightarrow \mathscr{O}^{A} \rightarrow \mathscr{A} \rightarrow 0
$$


Note that when $U$ is holomorphically convex, $H^{p}\left(U, \mathscr{O}^{A}\right)=0$, for all $p>0$, due to [3] and the well-known case $A=\mathbb{C}$. We have then the commutative diagram

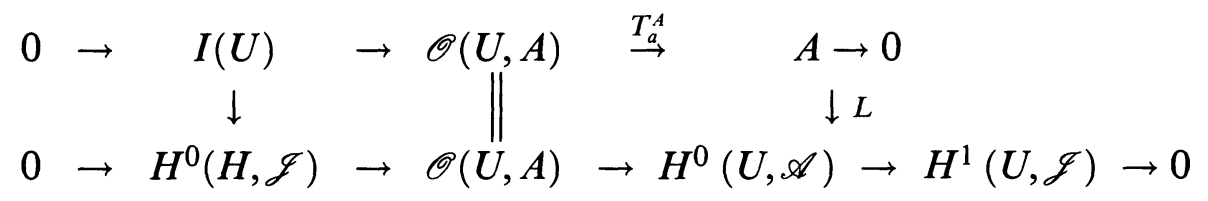

The ideal $\operatorname{Ker} L$ is isomorphic, because of the snake lemma construction, to the $A$-module $H^{0}(U, \mathcal{J}) / I(U)$. In fact, $H^{0}(U, \mathcal{J}) \simeq$ $\operatorname{Ker} L \oplus I(U)$. We obtain also the exact sequence,

$$
0 \rightarrow I(U) \rightarrow H^{0}(U, \mathscr{J}) \stackrel{T_{a}^{U}}{\rightarrow} A \stackrel{L}{\rightarrow} H^{0}(U, \mathscr{A}) \rightarrow H^{1}(U, \mathscr{J}) \rightarrow 0
$$

and therefore, $H^{1}(U, \mathscr{J}) \simeq H^{0}(U, \mathscr{A}) / \operatorname{Im} L$.

On the other hand, the exact sequence of sheaves

$$
0 \rightarrow \mathscr{N}_{a} \rightarrow\left(\mathscr{O}^{A}\right)^{n} \stackrel{\lambda_{a}}{\rightarrow} \mathcal{J} \rightarrow 0
$$

produces the exact cohomology sequence

$$
\begin{aligned}
0 \rightarrow \mathscr{N}_{a}(U) & \rightarrow \mathscr{O}(U, A) \stackrel{n}{\rightarrow} H^{0}(U, \mathscr{J}) \rightarrow H^{1}\left(U, \mathscr{N}_{a}\right) \rightarrow 0 \rightarrow \cdots \\
\cdots & \rightarrow 0 \rightarrow H^{p-1}(U, \mathcal{J}) \rightarrow H^{p}\left(U, \mathscr{N}_{A}\right) \rightarrow 0 \rightarrow \cdots
\end{aligned}
$$

We then have

$$
H^{1}\left(U, \mathscr{N}_{a}\right) \simeq H^{0}(U, \mathscr{J}) / I(U) \simeq \operatorname{Ker} L
$$

and

$$
H^{p}\left(U, \mathscr{N}_{a}\right) \simeq H^{p-1}(U, \mathscr{J}), \text { for } p>1 .
$$

We have proved:

Proposition 2.4. The morphism $L: A \rightarrow H^{0}(U, \mathscr{A})$ is

(i) a monomorphism iff $H^{0}(U, \mathscr{J})=0$ iff $H^{1}\left(U, \mathscr{N}_{a}\right)=0$

(ii) an epimorphism iff $H^{1}(U, \mathcal{J})=0$ iff $H^{2}\left(U, \mathscr{N}_{a}\right)=0$.

Note that $\operatorname{Ker} L$ consists of the elements $x$ in $A$ whose local analytic spectrum is empty. Therefore, $L(x)=0$ implies $x^{n+1}=0$. If $A$ has no nilpotent elements, $\operatorname{Ker} L=0$ and $H^{0}(U, \mathscr{J})=I(U)$.

Definition. We shall say that $A$ is $a$-representable if

(i) $\operatorname{sp}(a)$ is holomorphically convex, and

(ii) $H^{1}\left(\operatorname{sp}(a), \mathscr{N}_{a}\right)=0, H^{2}\left(\operatorname{sp}(a), \mathscr{N}_{a}\right)=0$.

Note that the first condition ensures the existence of a basis for neighborhoods of $\operatorname{sp}(a)$ made up of holomorphically convex open sets, 
while the second says that $L$ is an isomorphism for a basis of neighborhoods of $\operatorname{sp}(a)$. Hence, $A=H^{0}(\operatorname{sp}(a), \mathscr{A})$.

If $n=1$, and $\operatorname{sp}(a)$ has no interior, $A$ is $a$-representable: in this case, $\mathscr{N}_{a}=0$, for if $g \in \mathscr{N}_{a}(V)$, then $\left.g\right|_{V \cap(\mathbb{C}-\operatorname{sp}(a))}=0$, and hence, $g=0$.

Finally, we wish to compare $a$-representability and the unique extension property [4].

THEOREM 2.5. Suppose that $\operatorname{sp}(a)$ is holomorphically convex, and that the $n$-tuple $a=\left(a_{1}, \ldots, a_{n}\right)$ (considered as a family of operators from $A$ to $A$ ) has the unique extension property. Then $A$ is $a$ representable.

Proof. Consider the sheaf complex $K=K(\mathscr{O}, \alpha)$, where, for each open set $V$,

$$
K^{r}(V)=\mathscr{O}\left(V, \Lambda_{A}^{r}\left(A^{n}\right)\right)
$$

consists of analytic $A$-valued $r$-forms over $V$, and

$$
\alpha_{r}: K^{r} \rightarrow K^{r+1}
$$

is induced by the exterior product $\eta \rightarrow \sum_{j=1}^{n}\left(z_{j}-a_{j}\right) d z_{j} \wedge \eta$. For $n-1, \alpha$ may be written as

$$
\begin{aligned}
& \alpha_{n-1}\left(\sum_{i=1}^{n} f_{i} d z_{1} \cdots d \hat{z}_{i} \cdots d z_{n}\right) \\
& \quad=\sum_{i=1}^{n}(-1)^{i+1} f_{i}\left(z_{i}-a_{i}\right) d z_{1} \cdots d z_{n}
\end{aligned}
$$

so that $\operatorname{Ker} \alpha_{n-1}(z)$ is the stalk $\mathscr{N}_{a_{z}}$ (save a sign), and $\operatorname{Ker} \alpha_{n-1}=\mathscr{N}_{a}$.

Now the unique extension property expresses that cohomology $H^{r}(K)=0$, for $r=0, \ldots, n-1$, that is, the sequence of sheaves

$$
0 \rightarrow K^{0} \underset{\alpha_{0}}{\rightarrow} K^{1} \underset{\alpha_{1}}{\rightarrow} \cdots \rightarrow K^{n-2} \underset{\alpha_{n-2}}{\rightarrow} \mathscr{N}_{a} \rightarrow 0
$$

is exact. Since the sheaves $K^{r}$ are acyclic, that is, $H^{i}\left(U, K^{r}\right)=0$ for holomorphically convex $U$ and $i>0$, we obtain $H^{p}\left(U, \mathscr{N}_{a}\right)=0$ for all $p>0$.

\section{REFERENCES}

[1] E. Albrecht, Functionalkalküle in mehreren veränderliche für stetige lineare Operatoren auf Banachraumen, Manuscripta Math., 14 (1974), 1-40.

[2] N. Bourbaki, Théories Spectrales, Hermann, Paris, 1967. 
[3] L. Bungart, Holomorphic functions with values in locally convex spaces and applications to integral formulas, Trans. Amer. Math. Soc., 111 (1964), 317-344.

[4] S. Frunza, The Taylor spectrum and spectral decompositions, J. Funct. Anal., 19 (1975), 390-421.

[5] T. Gamelin, Uniform Algebras, Chelsea (2nd ed.), N. Y., 1984.

[6] A. Khelemskii, Homological methods in Taylor holomorphic calculus of several operators in a Banach space, Russ. Math. Surveys, 36 no. 1, (1981), 139-192.

[7] M. Putinar, Elemente de teorie spectrala a reprezentarilor algbrelor Stein, Stud. Cerc. Mat., 29 (1984), 193-219.

Received October 20, 1987 and in revised form September 26, 1988.

Universidad de Buenos Aires

Pabellon I, Ciudad-Universitaria

(1428) CAPITAL Federal

Buenos Aires, Argentina 


\section{PACIFIC JOURNAL OF MATHEMATICS EDITORS}

\author{
V. S. VARADARAJAN \\ (Managing Editor) \\ University of California \\ Los Angeles, CA 90024-1555-05 \\ Herbert Clemens \\ University of Utah \\ Salt Lake City, UT 84112 \\ THOMAs ENRIGHT \\ University of California, San Diego \\ La Jolla, CA 92093
}

R. FINN

Stanford University

Stanford, CA 94305

HermanN FlaschKa

University of Arizona

Tucson, AZ 85721

VAughan F. R. Jones

University of California

Berkeley, CA 94720

STEVEN KeRCKHOFF

Stanford University

Stanford, CA 94305

\author{
RobION KIRBY \\ University of California \\ Berkeley, CA 94720 \\ C. C. MoOre \\ University of California \\ Berkeley, CA 94720
}

Harold Stark

University of California, San Diego

La Jolla, CA 92093

\section{ASSOCIATE EDITORS
R. ARENS
E. F. BECKENBACH
B. H. NeumanN
F. WoLF
K. YoshidA (1906-1982)}

\section{SUPPORTING INSTITUTIONS}

UNIVERSITY OF ARIZONA
UNIVERSITY OF BRITISH COLUMBIA
CALIFORNIA INSTITUTE OF TECHNOLOGY
UNIVERSITY OF CALIFORNIA
MONTANA STATE UNIVERSITY
UNIVERSITY OF NEVADA, RENO
NEW MEXICO STATE UNIVERSITY
OREGON STATE UNIVERSITY

\author{
UNIVERSITY OF OREGON \\ UNIVERSITY OF SOUTHERN CALIFORNIA \\ STANFORD UNIVERSITY \\ UNIVERSITY OF HAWAII \\ UNIVERSITY OF TOKYO \\ UNIVERSITY OF UTAH \\ WASHINGTON STATE UNIVERSITY \\ UNIVERSITY OF WASHINGTON
}

The Supporting Institutions listed above contribute to the cost of publication of this Journal, but they are not owners or publishers and have no responsibility for its content or policies.

Mathematical papers intended for publication in the Pacific Journal of Mathematics should be in typed form or offset-reproduced (not dittoed), double spaced with large margins. Please do not use built up fractions in the text of the manuscript. However, you may use them in the displayed equations. Underline Greek letters in red, German in green, and script in blue. The first paragraph must be capable of being used separately as a synopsis of the entire paper. In particular it should contain no bibliographic references. Please propose a heading for the odd numbered pages of less than 35 characters. Manuscripts, in triplicate, may be sent to any one of the editors. Please classify according to the scheme of Math. Reviews, Index to Vol. 39. Supply name and address of author to whom proofs should be sent. All other communications should be addressed to the managing editor, or Elaine Barth, University of California, Los Angeles, California 90024-1555-05.

There are page-charges associated with articles appearing in the Pacific Journal of Mathematics. These charges are expected to be paid by the author's University, Government Agency or Company. If the author or authors do not have access to such Institutional support these charges are waived. Single authors will receive 50 free reprints; joint authors will receive a total of 100 free reprints. Additional copies may be obtained at cost in multiples of 50 .

The Pacific Journal of Mathematics is issued monthly as of January 1966. Regular subscription rate: $\$ 190.00$ a year (5 Vols., 10 issues). Special rate: $\$ 95.00$ a year to individual members of supporting institutions.

Subscriptions, orders for numbers issued in the last three calendar years, and changes of address should be sent to Pacific Journal of Mathematics, P.O. Box 969, Carmel Valley, CA 93924, U.S.A. Old back numbers obtainable from Kraus Periodicals Co., Route 100, Millwood, NY 10546.

The Pacific Journal of Mathematics at P.O. Box 969, Carmel Valley, CA 93924 (ISSN 0030-8730) publishes 5 volumes per year. Application to mail at Second-class postage rates is pending at Carmel Valley, California, and additional mailing offices. Postmaster: send address changes to Pacific Journal of Mathematics, P.O. Box 969, Carmel Valley, CA 93924.

\section{PUBLISHED BY PACIFIC JOURNAL OF MATHEMATICS, A NON-PROFIT CORPORATION}

Copyright (C) 1990 by Pacific Journal of Mathematics 


\section{Pacific Journal of Mathematics}

\section{Vol. 141, No. 2 December, 1990}

Ulrich F. Albrecht, Locally $A$-projective abelian groups and

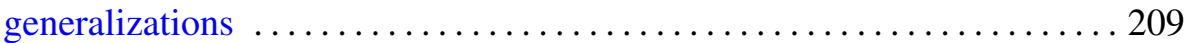

Michel Carpentier, Sommes exponentielles dont la géométrie est très belle: $p$-adic estimates ..................................... 229

G. Deferrari, Angel Rafael Larotonda and Ignacio Zalduendo, Sheaves and functional calculus

Jane M. Hawkins, Properties of ergodic flows associated to product odometers ........................................287

Anthony To-Ming Lau and Viktor Losert, Complementation of certain subspaces of $L_{\infty}(G)$ of a locally compact group ............... 295

Shahn Majid, Matched pairs of Lie groups associated to solutions of the

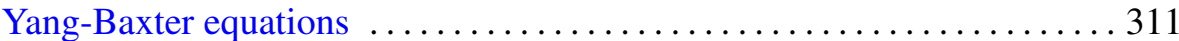

Diego Mejia and C. David (Carl) Minda, Hyperbolic geometry in $k$-convex

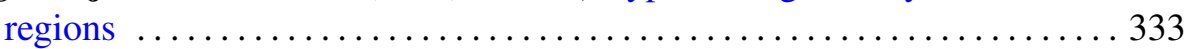

Vladimír Müller, Kaplansky's theorem and Banach PI-algebras ...........355

Raimo Näkki, Conformal cluster sets and boundary cluster sets coincide . . . 363

Tomasz Przebinda, The wave front set and the asymptotic support for $p$-adic groups

R. F. Thomas, Some fundamental properties of continuous functions and topological entropy 